\title{
Editorial
}

\section{Indoor Air and Exposure: Selected papers from INDOOR AIR 2002}

\author{
Journal of Exposure Analysis and Environmental Epidemiology (2004) 14, S1-S3. doi:10.1038/sj.jea.7500377
}

It could be said that exposure analysis emerged as a distinct discipline - indeed, this journal was founded - as an outgrowth of the study of indoor air. The founders of this new discipline, steeped in the historical study of air pollution, recognized that a focus limited to the ambient environment was becoming less relevant. They shifted their study of hazards to the "interface" between the receptor and the environment, and they turned their attention first to the most obvious "microenvironment," indoors, where people often experience their greatest exposures.

Awareness of exposures in indoor environments increased with the emergence of "sick building syndrome" among office workers and home dwellers. Arguably, this phenomenon was an unintended consequence of building design changes in response to the energy crises, plus the increased use of new chemicals and plastics. Other factors also helped shift the attention of public health researchers and the public toward the indoor environment, such as perceived improved ambient air quality as a result of the early successes of federal clean air policies aimed at outdoor emissions. The increasing importance of risk assessment in the application of pollutioncontrol regulations also demanded exposure estimates of greater sophistication and accuracy.

The indoor environment is central to public health because, to paraphrase the famous Willie Sutton quote, "that's where the people are." Other than as a loci of receptors, is there anything that makes indoor air intrinsically more interesting than outdoor air from a scientific point of view? Admittedly, some sources are uniquely building related (e.g., cleaning agents, volatile organic compounds (VOCs) from building materials and personal care products), and some contaminant dynamics operate only in buildings (e.g., distribution of particles and gases by mechanical ventilation systems and infiltration of soil gases). While indoor environments are a microcosm of most urban settings, the effective air exchange in buildings is much lower than in the free atmosphere, even in urban areas. Hence, a person is maybe 1000 times more likely to inhale a chemical molecule if it is emitted indoors rather than outdoors (Nazaroff et al., 2004). Significantly, compounding the potential importance of the indoor environment is the fact that some emissions have greater source strength indoors than outdoor on a per area basis.

The First International Indoor Climate Symposium was convened in Copenhagen, Denmark in 1978. Never before had a major international meeting been devoted exclusively to the emerging issues unique to the indoor climate. The opportunity to meet and hear fellow scientists established a nexus for the growing community of indoor environment researchers. Subsequent meetings in this series were held in Amherst (MA), USA (1981), Stockholm, Sweden (1984), Berlin, West Germany (1987), Toronto, Canada (1990), Helsinki, Finland (1993), Nagoya, Japan (1996), Edinburgh, Scotland (1999), and Monterey (CA), USA (2002). A steady rise in the number of presentations on indoor air quality and exposures was seen as the conference series progressed.

The International Society of Exposure Analysis (ISEA) was born out of the revelations and momentum that Dr. Lance Wallace and the Total Exposure Assessment Methodology (TEAM) studies created. It was Dr. Wallace's persistence throughout the 1980s that generated this authoritative database that demonstrated subjects' exposures to pollutants in indoor air vis-a-vis their outdoor exposures. The sparks this research started were fanned into a flame at the 1989 Air Pollution Control Association Specialty Conference, Total Exposure Assessment Methodology: A New Horizon in Las Vegas, Nevada. Most everyone present at the conference came to recognize that it was time to institutionalize total exposure assessment and, particularly, to give indoor environment exposure its due. The ISEA was conceived over drinks in a casino bar. While it can be dangerous to name names and risk unintentionally omitting someone, many of ISEA's fathers (and mothers) already had strong ties to the emerging field of indoor air research: Gerry Akland, Julian Andelman, Mike Dellarco, Joan Daisey, Judy Graham, Michael Lebowitz, Paul Lioy, Tom McKone, Lars Molhave, Demetrios Moschandreas, Wayne Ott, Edo Pellizari, Bernd Seifert, Kirk Smith, and Jack Spengler, etc... starting to see a resemblance?

The Ninth International Conference on IAQ and Climate was convened from 30 June to 5 July 2002 in Monterey (CA), USA. INDOOR AIR 2002 attracted a record number of participants $(>1000)$ from 43 countries and featured 12 plenary lectures and more than 700 contributed papers. Brief (six-page) versions of all presented papers were published in the conference proceedings (Copies of the Proceedings are available on CD through www.indoorair2002.org or www.isiaq.org.). This special issue of the Journal of Exposure 
Analysis and Environmental Epidemiology presents complete reports of a selection of INDOOR AIR 2002 papers identified as most directly related to exposure analysis.

The largest proportion of the papers at the 2002 conference that focused on a single topic addressed issues of indoor biological contamination. Most of these papers were concerned with measurement or clean-up, but several groups reported on related health impacts or exposures. Haverinen et al. conducted an intervention study of students' health symptoms over time (before and after repairs) at a moisture-damaged school. Foarde and Berry also evaluated the school environment, comparing biocontaminant levels from carpeted floors and hard floors. In fact, almost half of the papers in this Special Issue focus on exposures to children, either in their homes or at school.

Adgate et al. measured children's VOC exposures in a probability sample in Minnesota and observed the familiar pattern: personal exposures exceeded indoor area levels, which in turn exceeded outdoor levels. Serrano et al. conducted a year-long study in Mexico City homes, and they compare personal samples among family members with indoor and outdoor VOC concentrations. They found that certain compounds had notably higher indoor sources and, while personal exposure measurements were comparable to indoor levels for some compounds, for others, the personal exposures were much higher than indoor levels.

Sax et al. looked at differences in VOC source emission rates using a data set of indoor and outdoor VOC measurements plus air-exchange rates in New York City and Los Angeles homes. The authors determined which compounds had predominantly indoor sources and found seasonal differences for several VOCs. Glas et al. measured personal VOC exposures in office buildings in Sweden and found that for most chemicals inter-personal was more important than between-building variability.

Raw et al. summarize a large, national survey of indoor air pollutants in English homes, and they found that indoor sources were much more critical than ventilation. Takaro et al. assessed environmental interventions in lowincome homes, which significantly reduced children's exposures to asthma triggers. The localized impacts of indoor activities on PM exposures, dubbed the "personal cloud" effect were studied by Ferro et al., who looked at a range of specific activities, such as those that disturb dust reservoirs in the household.

Several papers addressed PM exposures from indoor combustion of solid fuels in stoves for cooking or heating. Though not seen in industrialized countries, such stoves are widespread throughout the developing world, and they lead to excessively high indoor PM. The World Bank funded a symposium on Indoor Air Quality and Health in Developing Countries at INDOOR AIR 2002 and sponsored attendance for several dozen authors. A number of papers from this special symposium are included in this issue.
Balkrishnan et al. conducted stratified random sampling in rural homes in India where gas or solid-fuel stoves were used. The researchers used their field data to develop a model to predict population exposures based on housing and fuel characteristics. Bruce et al. compared PM and carbon monoxide exposures by stove type and housing characteristics for a population of rural Guatemalan children. Schei et al. also studied Guatamalan homes with cooking stoves, finding that children's asthma symptoms were associated with PM exposures. Qian et al. analyzed the data collected in a large epidemiologic study of respiratory health effects among school children living in four Chinese cities. The data showed greater effects for exposures to heating as compared with cooking coal.

In Italy, Simoni et al. conducted epidemiologic studies of two population samples in Italy - one in a rural area and one in an urban area - finding associations between indoor pollution exposures and acute respiratory effects. Acute respiratory illnesses and symptoms were associated with nitrogen dioxide and/or PM exposures.

Nazaroff and Singer present a provocative assessment of IAQ in smoker's homes in the context of federal regulations on the health risks of the hazardous air pollutants in tobacco smoke, which do not fall under existing regulation. They report concentrations of several environmental tobacco smoke (ETS) compounds in excess of regulatory reference values. Kim et al. report a significant correlation between urinary cotinine levels in nonworking women in Seoul and ETS concentrations in their homes.

By design, this special issue of JEAEE omits important exposure routes, such as diet and dermal contact, as these papers focus only on inhalation exposures and indoor climate. As a collection of papers on indoor air, this issue excludes many important aspects, for example, chemical dynamics and ventilation engineering. The organizers of INDOOR AIR 2002 have planned separate special issues of archival journals featuring invited full-length papers from the conference. In addition to indoor air and exposure, other journals will address the indoor air themes of chemical dynamics, building science, health, and bioaerosols.

The completion of this special issue required the efforts of many individuals, and as first-time journal editors, we want to acknowledge the substantial help we needed and received. Dr. Edo Pellizzari, the Journal's editor, gave us his full support and guidance as we made our way through this process. We want to thank the numerous peer reviewers, who supplied excellent comments and guidance for the revisions of these papers. Jessica Marshall provided additional technical editing support for some of the papers in this issue. Hal Levin gave essential encouragement and editorial assistance, and as president of INDOOR AIR 2002, provided the financial backing for the printing and distribution of this issue to all conference attendees - almost tripling the number of subscription copies. Finally, we are indebted to those 
INDOOR AIR 2002 presenters, who accepted our invitation and produced manuscripts, responded to reviewers and editors' comments, and completed their papers, on time (and under budget).

One final observation that bodes well for the future of our fraternal twin fields of indoor air and exposure analysis/ environmental epidemiology: five of the fourteen papers in this volume were authored by young investigators just completing their doctorates (Ferro, Haverinen, Sax, Schei, and Serrano). We wish them good luck in early careers.
Jed M. Waldman, California Department of Health Services, Richmond, CA, USA. E-mail: JWaldman@dhs.ca.gov

Deborah H. Bennett, Harvard School of Public Health, Boston, MA, USA

Sumi Mehta

Health Effecs Institute, Boston, MA, USA 